\title{
PhD students' excellence scholarships and their relationship with research productivity, scientific impact, and degree completion
}

Vincent Larivière

EBSI, Université de Montréal

\begin{abstract}
This paper examines the relationship between excellence scholarships and research productivity, scientific impact, and degree completion. Drawing on the entire population of doctoral students in the province of Québec, this paper analyzes three distinct sources of data: students, excellence scholarships, and scientific publications. It shows that funded students publish more papers than their unfunded colleagues, but that there is only a slight difference between funded and unfunded PhD students in terms of scientific impact. Funded students, especially those funded by the federal government, are also more likely to graduate. Finally, although funding is clearly linked to higher degree completion for students who did not publish, this is not true of those who managed to publish at least one paper during the course of their PhD. The paper concludes with a discussion of the implication of the findings for Canadian science policy.
\end{abstract}

\section{Résumé}

À partir de trois différentes sources de données relatives à l'ensemble de la population de doctorants du Québec (listes d'étudiants, de boursiers et d'articles savants), le présent article examine les liens qui existent entre les bourses d'excellence et la productivité en recherche, l'impact scientifique et l'obtention d'un diplôme. Il démontre que les étudiants financés publient davantage que ceux qui ne le sont pas, mais qu'il n'existe qu'une infime différence entre les deux groupes d'étudiants en termes d'impact scientifique. 
Par ailleurs, les étudiants financés sont plus susceptibles d'obtenir leur diplôme, et cette relation est encore plus forte si le financement provient du gouvernement fédéral. Enfin, bien que le financement soit clairement associé à un taux plus élevé d'obtention de diplôme chez les étudiants qui n'ont rien publié pendant leurs études doctorales, cette relation disparaît chez les étudiants qui ont publié au moins un article. Une discussion portant sur les conséquences des résultats obtenus sur la politique scientifique du Canada conclut le présent article.

Analysis of the relationship between researchers' funding and their research output has typically been performed on established researchers (Ali, Bhattacharyya \& Olejniczak, 2010; Boyack \& Börner, 2002; Campbell et al., 2010). However, they are not the only group of researchers receiving money for research: graduate students, either at the MA, MSc, or PhD level, account for a significant proportion of research funds in Canada. More specifically, in 2008-2009, about a third of federal research council research funding in the social sciences and humanities, $15 \%$ of their funding in the natural sciences and engineering, and $6 \%$ of the funding in the medical sciences went to fellowships and scholarships. ${ }^{1}$ Overall, more than $\mathrm{C} \$ 300$ million was granted by federal research councils in 2008-2009. At the provincial level, roughly $20 \%$ of all research funding goes to scholarships (CNCS-FEUQ, 2008).

Despite the magnitude of this funding and the importance of graduate programs to the scientific community, no study has yet analyzed the relationship between this funding and students' research productivity, scientific impact, and degree completion in Canada. This paper aims to provide such analysis for the entire population of $\mathrm{PhD}$ students enrolled in Québec universities during the 2000-2007 period. Three datasets are used: (a) all graduate students enrolled in a PhD program at a Québec university, (b) the list of "excellence" scholarships granted by the three federal research councils, Canadian Institutes of Health Research (CIHR), Natural Sciences and Engineering Research Council of Canada (NSERC), and Social Sciences and Humanities Research Council of Canada (SSHRC), and the three provincial research councils, Fonds de la recherche en santé du Québec (FRSQ), Fonds québécois de recherche sur la société et la culture (FQRSC), and Fonds québécois de la recherche sur la nature et les technologies (FQRNT), and (c) Thomson Reuters' Web of Science bibliometric database of papers authored by Québec researchers. Consequently, funding analyzed in this study is limited to excellence scholarships awarded directly to students through peer review by these six councils and, hence, does not include "discretionary" scholarships provided by advisors through their own research fund or funding coming from teaching or research assistantships.

The scholarships awarded by the six research councils comprise tax-free annual salaries: $\mathrm{C} \$ 20,000$ is awarded by the Québec provincial research councils, and $\mathrm{C} \$ 20,000$ or $\mathrm{C} \$ 35,000$ is awarded at the level of the federal Canadian councils, where two kinds of scholarships are available depending on the overall ranking of the student. Except for the C $\$ 20,000$ SSHRC scholarship, which can be attributed for four years, these scholarships are awarded for a maximum of three years. Although provincial legislation prevents federal and provincial scholarships from being held concurrently, students awarded 
a provincial scholarship for the first three years of their doctorate can obtain a federal scholarship for their fourth year. Given that students who are awarded both federal and provincial scholarships must accept the federal scholarship, and that the average amount awarded in federal scholarships is greater, we can infer that, generally, students funded at the federal level scored better in the review process than those funded at the provincial level. Because their "paid" working hours, both within and outside the university, are limited to a strict minimum, these scholarships are generally the main source of income of those who hold them.

This study cannot measure the specific effect of these scholarships on PhD students' productivity, impact, and degree completion because those same scholarships are awarded on a review basis, which takes publications into account. In other words, the fact that a student has published prior to applying for a scholarship is likely to have a positive influence on the success of his or her application. Hence, the only question we can answer ${ }^{2}$ is whether there is a relationship between having received a scholarship and (a) publication activity during their $\mathrm{PhD}$, (b) citations, and (c) degree completion. If such a relationship does exist, we can conclude that research councils were successful in choosing the young researchers with the greatest research potential. On the other hand, one might argue that many unfunded students possess equivalent research potential, but are not able to fulfill it because they lack the funding necessary to catalyze it. We could, thus, say that those they funded were among the students with the most research potential. Actually, the only way to sort out this impasse would be to arbitrarily divide "fundable" students into two groups, fund one, leave the other unfunded, and then compare their subsequent research performance. However, this method would not be considered ethical.

The following section briefly examines the results of related studies on students funding, publication patterns, and degree completion. The methods section describes the dataset, data compilation, and indicators used. The third section presents the results and discusses those results and the conclusion.

\section{Related studies}

Because general literature on student participation in scientific papers is scarce, only a few direct sources of information on the specific factors influencing such participation were found. Similarly, although several studies have analyzed the effect of funding on students' graduation, very few have linked their funding with their research productivity.

An important source of information on doctoral education found in the literature is the large-scale survey of doctoral students-more than 9,000 covering all disciplines-performed by Nettles and Millets (2006). It provides unique results on the effect of funding and supervisors on students' publication records. The authors divide the types of funding available to students during their doctorate into three categories: fellowships, research assistantships and teaching assistantships. As one could expect, students from different disciplines have varying degrees of access to this research funding. The disciplines with the highest proportion of students with fellowships are the humanities (69\%), followed by the social sciences (61\%), sciences and mathematics (59\%), engineering (50\%), and education (46\%). Nettles and Millett's study does not provide any indication of the amount received, and smaller fellowships might explain the higher percentage of students funded in the humanities. 
In terms of research assistantships, the tendency is quite different: $82 \%$ of students in engineering and $69 \%$ of students in science and mathematics worked as faculty members' assistants, but this percentage dropped to only $49 \%$ in the social sciences, $33 \%$ in humanities, and $28 \%$ in education. Finally, in all disciplines but education, a majority of students received teaching assistantships. These various types of funding were found to have a strong effect on the PhD students' participation in peer-reviewed papers. Students receiving fellowships were more likely to publish in education, sciences and mathematics, and the social sciences. Similarly, in all disciplines but the humanities, students who were research assistants published more papers. Teaching assistantships were positively linked with research productivity only in the humanities. Along the same lines, Buchmueller, Dominitz, and Hansen (1999) have positively linked students' research assistantships with research productivity, using a sample of doctoral students in economics. Unsurprisingly, working with productive faculty members also increased students' research output. Similarly, Larivière (2012) has demonstrated a positive relation between specialties where the average amount in funding received by professors was higher and the percentage of doctoral students who published at least one paper This is not surprising because research funds received by faculty members are often used to provide scholarships or to hire students for work on research projects, which, in turn, increase both student participation in peer-reviewed papers and the probability of faculty members being funded again.

Although no studies have analyzed the effect of funding on the scientific impact of students' papers, Campbell et al. (2010) provide evidence of a clear relationship between the funding of researchers and their citation rates. Similar results were obtained by Peritz (1990), as well as in a number of confidential reports made by various bibliometric organizations throughout the world. Finally, several studies focusing on higher education have positively linked students' funding with degree completion (Bowen \& Rudenstine, 1992; Ehrenberg \& Mavros, 1995; Ethington \& Pisani, 1993).

\section{Method}

\section{Students' Database}

Given that the status (student, professor, postdoctoral fellow, etc.) of individual authors does not appear in the byline of papers or in bibliographical databases, a list of doctoral students' full names is needed to find papers they authored. Although all Québec universities have their own enrolment lists, expected differences in format and content, as well as difficulties of access, discouraged their use. Hence, it was decided to use the Québec government's administrative database of university enrolment, the Gestion des données sur l'effectif universitaire (GDEU). This database contains the names-essential information for this study-of all university students in the province of Québec. ${ }^{3}$ To find publications authored by doctoral students, the database of scientific papers written by authors from the province of Québec and the database of university enrolment were cross-searched for matching names. This database was provided for the 2000-2007 period. More specifically, the dataset analyzed in this study contains PhD students that either (a) enrolled in a PhD program between winter 2000 and fall 2007 or (b) enrolled before winter 2000 but were still registered or graduated at any point after 2000. Hence, 
students who completed their PhD in 1998 or 1999 are excluded from the dataset, as well as students who joined a PhD program after 2007. On the whole, the list contains 27,397 distinct doctoral students, with 2,838 (10.4\%) having changed program at least once during the period under study.

To compare the results obtained across the spectrum of disciplines, the 866 distinct doctoral programs of the students included in the GDEU database were categorized into 42 specialties and nine disciplines. This classification scheme used for categorizing doctoral programs was based on the 2000 revision of the U.S. Classification of Instructional Programs (CIP)-from which the Canadian CIP is adapted-developed by the U.S. Department of Education's National Center for Education Statistics (NCES). A CIP-based discipline could not be attributed to 232 doctoral students (o.8\% of the dataset), mainly because the names of the programs in question were too general (e.g. "PhD program") or because they contained more than one discipline; these were excluded from the analysis.

\section{Funded Students' Database}

The list of all funded students was built by combining the three databases of the federal research councils (CIHR, NSERC, and SSHRC) and the two databases of the provincial councils (FQRNT/SC and FRSQ). The information provided by the councils was not of homogeneous quality-although the federal data contained information on the exact amount received by students for each year during which they were funded, Québec research councils did not provide any information on the yearly amount received. These scholarships can either be awarded to students studying in Québec or to students studying in other Canadian provinces. ${ }^{4}$ Although we know that the amount of provincial grants is $\mathrm{C} \$ 20,000$ annually, some students-such as those who interrupt their studies-might receive less than $\mathrm{C} \$ 20$,000. Another limitation is that funding from the FQRSC and FQRNT was merged, which makes it difficult to analyze the specific effect of each provincial research council. Because of these limitations, this paper is limited to the analysis of students funded or unfunded through any of the excellence scholarships, and, for funded students, analysis of the difference between those funded by the federal and the provincial programs. When data was broken down by source of funding, students who received both provincial and federal funding were considered in both categories.

The process of matching the list of funded students with the list of all Québec students from the GDEU database was performed using in-house software. The matching was performed on a surname and given name basis and manually validated. Out of the 7,491 grants that were awarded, 5,766 were matched to a student in our list for a total of 4,672 distinct students. Hence, 1,725 grants were awarded to students who pursued a doctoral degree outside the province or country-these scholarships can either be attributed to students studying in Québec or to Canadian or Québécois students studying outside Québec. It is also possible that a small proportion of these unmatched students are actually false negatives (i.e., students who indeed pursued doctoral studies in Québec but could not be matched because the spelling of their surname or given name changed).

Finally, an important limitation of our analysis is the fact that doctoral students can have other sources of funding: institutional or "discretionary" scholarships (i.e., scholarships given by the students' supervisor), teaching assistantships, research assistantships, or external jobs. Data compiled on these supplementary sources of funding, however, is 
not compiled in a consistent manner and does not exist at the level of the entire population. The funding covered in this paper is the most prestigious available to PhD students, and, contrary to what is generally the case for other sources, is obtained through a very competitive peer-review process.

\section{Disambiguation of Students' Papers}

This paper includes the whole population of $\mathrm{PhD}$ students enrolled in Québec universities between 2000 and $2007(\mathrm{~N}=27,397)$. Papers authored by these students during the 2000-2007 period were retrieved from Thomson Reuters' Web of Science (WoS) by matching the names of all Québécois doctoral students with those of authors with at least one institutional address from Québec. Although bibliographic sources other than the WoS, such as Scopus and Google Scholar, can be used for bibliometric analyses, the WoS remains the source with the most consistent coverage and can still be considered as the gold standard against which these new databases are assessed. Given that the WoS does not index the complete first name of authors, but only their initials, this rough match generates a high number of false positives-papers authored by other researchers with same name as a doctoral student-which were removed using both manual and automatic validation. More details on the disambiguation process can be found in Larivière (2010). After the disambiguation process, 31,738 author-article combinations were retained (out of the 313,367 originally obtained with the first match) for 25,159 distinct papers and 8,468 doctoral students with at least one paper.

\section{Bibliometric Database and Indicators}

Publication counts presented in this paper are based on the number of articles, notes, and review articles to which authors from Québec contributed during the 2000-2007 period. Editorials, book reviews, letters to the editor, and meeting abstracts are excluded from the analysis because they are not generally considered original contributions to scholarly knowledge and because they are not peer reviewed (Moed, 1996). These numbers are based on full counting of papers, as opposed to fractional counting sometimes used in bibliometrics. Hence, each individual or organization contributing to a paper is assigned one full contribution-instead of a fraction of a contribution-irrespective of rank in the author order. Papers are considered as being authored by doctoral students when at least one of the authors is enrolled in a PhD program at a Québec university during the year of publication or has been enrolled during the year prior to the year of publication. In other words, in line with Lee (2000), doctoral students' papers are still considered as such until one year after they graduate or leave the program. Note that this practice is also found in large-team particle physics experiments, where researchers get to sign the papers coming out of the experiment until one year after they leave the team (Biagioli, 2003).

Citation measures account for all citations received by a given paper, from its publication year to the end of 2011. To compare data between different specialties, each article's number of citations is divided by the average number of citations received by papers of the same discipline published that same year (Moed, De Bruin and van Leeuwen, 1995; Schubert and Braun, 1986). Self-citations are excluded and impact measures are normalized so that when the average of relative citations (ARC) is above 1, a given article is cited 
above the world average for the same field. Conversely, an ARC below 1 means that the number of citations received is below the world average. Finally, the well-known limitations of bibliometrics apply to this analysis. Indeed, the measures presented here cannot include all documents published by doctoral students, because bibliometric databases do not index all the scholarly literature published worldwide. This limitation is more important in the social sciences and the humanities, where the methods of counting articles pose two main problems: (a) there is no coverage of research output in media other than journal articles (Larivière et al., 2006) and (b) there is very limited coverage of research output in the form of articles written in languages other than English (Archambault et al., 2006). The fact that the WoS was used instead of Google Scholar does little to affect these limitations. Although Google Scholar indexes a larger proportion of the current literature than the WoS, its coverage of older records is weaker than that of the WoS, and it is, from a practical point of view, impossible to use for large-scale analyses.

\section{Results}

Table 1 presents the percentage of doctoral students who have received a scholarship from any of the six research councils ${ }^{5}$. Globally, it shows that about $17 \%$ of doctoral students in our population have received one of these scholarships, and that most of these scholarships were obtained from the federal government. The only disciplines for which the main sources of scholarships are the provincial councils are business, management, and education. We clearly see that students in the medical sciences and health are more likely to be funded, followed by students in the humanities, sciences, and social sciences. A smaller proportion of PhD students in applied or professional fields such as engineering, education, and business hold scholarships, which is likely a reflection of industry funding and part-time studies. These differences can also be explained by the number of applications and the differences in success rates of applications. Although at the federal level, 64\%, 32\%, and 22\% of the applications reviewed by NSERC, CIHR, and SSHRC, respectively, were funded, at the provincial level, only $42 \%, 34 \%$, and $33 \%$ of the applications reviewed by FRQNT, FRSQ, and FQRSC received funding (CSE, 2010).

Although it is not shown in Table 1, a larger proportion of students who enrolled at the beginning of the period studied relative to those who enrolled at the end of the same period obtained a scholarship. This can be explained by the fact that the former group of students (a) had more time to improve their research record and (b) probably applied on a yearly basis, which, from a strictly probabilistic point of view, increased their chances of landing a scholarship.

\section{Research Productivity}

Two measures of research productivity are presented in Figure 1: the percentage of students with at least one paper (A) and the average number of papers (B). Both measures converge and show that, when all disciplines are combined, funded students are more than twice as productive as their colleagues who did not receive such funding. Although this is observed in each of the disciplines, the difference between funded and unfunded $\mathrm{PhD}$ students is less pronounced in the basic medical sciences and sciences. This is likely a reflection of the fact that professors of these disciplines receive more funding than their 
Table 1.

Percentage of PhD Students who have Received a Scholarship from the Federal or Provincial Research Councils, by Source and Discipline, 2000-2007

\begin{tabular}{|c|c|c|c|c|c|c|c|}
\hline \multirow{2}{*}{ Research Area } & \multicolumn{2}{|c|}{ Federal } & \multicolumn{2}{|c|}{ Provincial } & \multicolumn{2}{|c|}{$\begin{array}{l}\text { Federal or } \\
\text { provincial }\end{array}$} & \multirow{2}{*}{ All Students } \\
\hline & N. & $\%$ & N. & $\%$ & N. & $\%$ & \\
\hline $\begin{array}{l}\text { Basic Medical } \\
\text { Sciences }\end{array}$ & 620 & $17.4 \%$ & 443 & $12.4 \%$ & 970 & $27.2 \%$ & 3,567 \\
\hline $\begin{array}{l}\text { Business \& } \\
\text { Management }\end{array}$ & 59 & $4.2 \%$ & 85 & $6.1 \%$ & 128 & $9.2 \%$ & 1,389 \\
\hline Education & 72 & $4.7 \%$ & 102 & $6.6 \%$ & 157 & $10.2 \%$ & 1,536 \\
\hline Engineering & 370 & $8.2 \%$ & 241 & $5.4 \%$ & 498 & $11.1 \%$ & 4,502 \\
\hline Health Sciences & 89 & $14.0 \%$ & 68 & $10.7 \%$ & 140 & $22.0 \%$ & 635 \\
\hline Humanities & 521 & $13 \cdot 3 \%$ & 308 & $7.9 \%$ & 727 & $18.6 \%$ & 3,919 \\
\hline $\begin{array}{l}\text { Non-Health } \\
\text { Professional }\end{array}$ & 158 & $10.1 \%$ & 112 & $7.1 \%$ & 240 & $15 \cdot 3 \%$ & 1,569 \\
\hline Sciences & 698 & $14.2 \%$ & 360 & $7 \cdot 3 \%$ & 875 & $17.8 \%$ & 4,916 \\
\hline Social Sciences & 737 & $12.2 \%$ & 500 & $8.3 \%$ & 1,046 & $17.3 \%$ & 6,059 \\
\hline All Areas & 3,267 & $11.9 \%$ & 2,146 & $7.8 \%$ & 4,672 & $17.1 \%$ & 27,397 \\
\hline
\end{tabular}

colleagues in the social sciences and humanities (Larivière, 2012), which is then used to fund students. In other words, students in the medical and natural sciences who received no scholarships were more likely than their colleagues in the social sciences and humanities to obtain discretionary funding, either through their advisors or sources such as foundations dealing with specific illnesses.

Figure 2 presents the same indicators of research productivity for students funded by federal or provincial scholarships. As mentioned previously in this paper, federal scholarships provide, on average, a greater amount of funding than their provincial counterparts. Surprisingly, there is no noticeable difference in terms of research productivity, across all disciplines, between students funded by the federal government and those funded by the Québec government. Although in most disciplines provincial funding is linked to higher productivity, these differences are quite small, and the opposite is true in a few others. This suggests that the amount awarded to PhD students in scholarships, as well as their rank in the evaluation, has little effect on publication output. Being funded is what counts, whatever the amount awarded. 

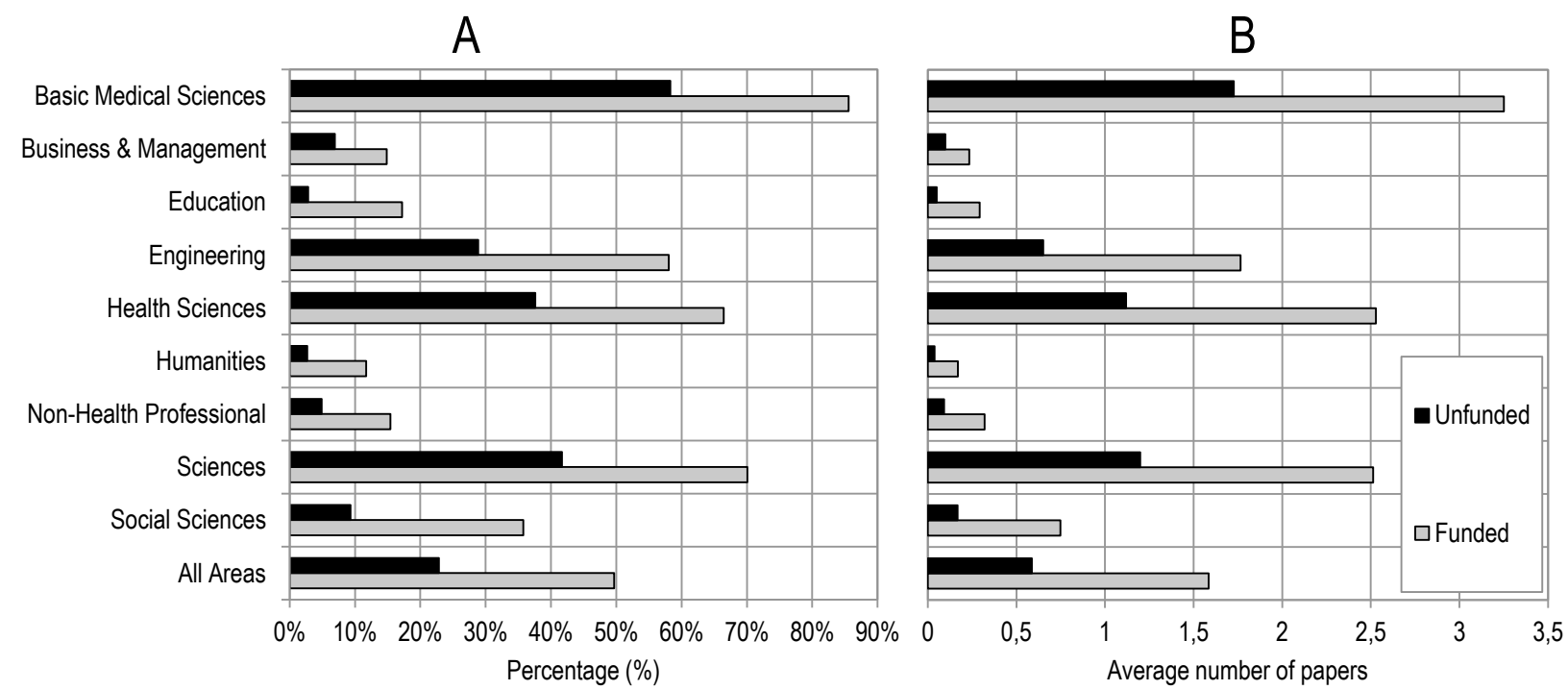

Figure 1. Comparing the productivity of funded and unfunded PhD students: A) Percentage of students with at least a paper, and B) Average number of papers of students, 2000-2007.
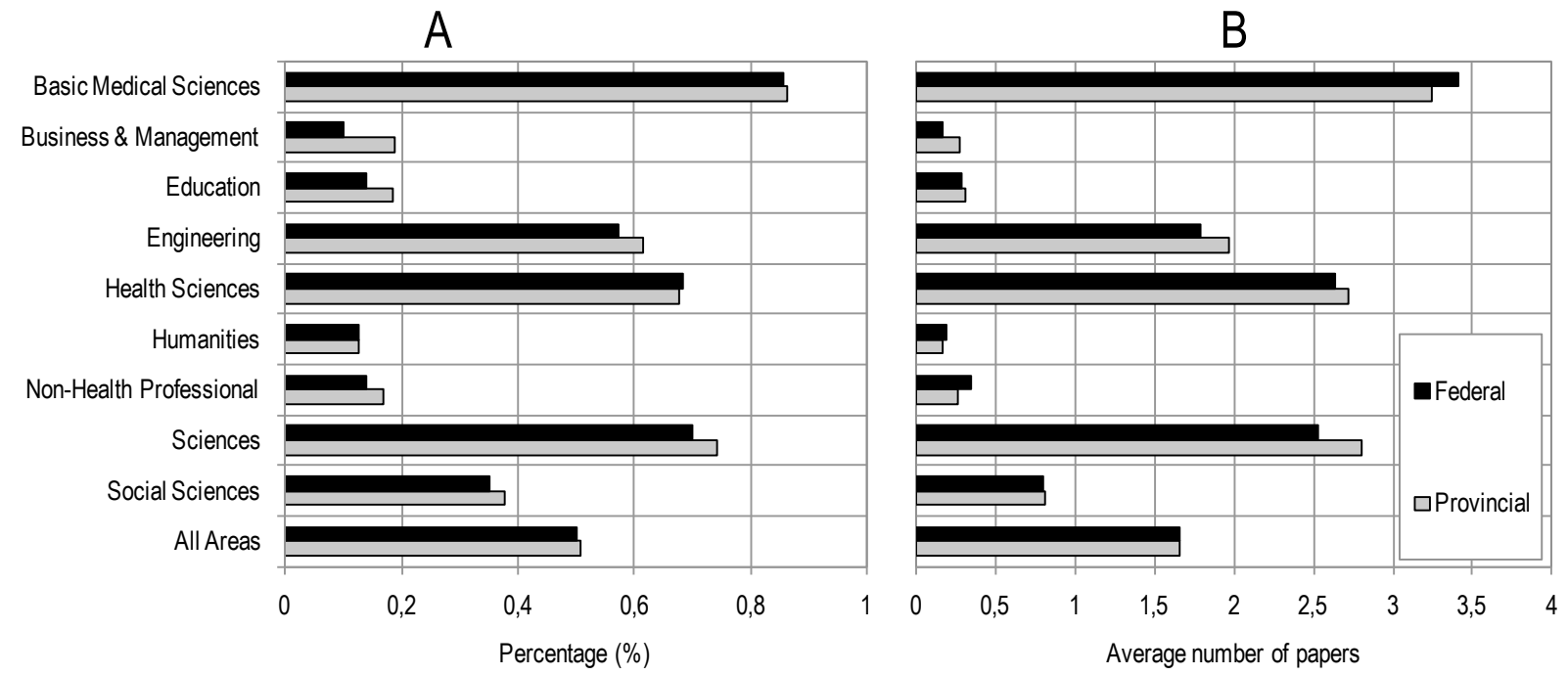

Figure 2. Comparing productivity of students funded by federal or provincial councils: A) Percentage of students with at least a paper, and B) Average number of papers of students, 2000-2007. 


\section{Scientific Impact}

Figure 3 presents the field-normalized citation rate of papers to which funded and unfunded students contributed (A) and of papers authored by students funded by federal or provincial research councils (B). Figure 3.A shows that funded students' papers obtain, on average, slightly higher citation rates than those of their unfunded colleagues (1.32 vs. 1.24), and that the difference between the two groups' scores varies greatly among disciplines. However, in all disciplines but business and education, funded students' papers have more impact than those authored by unfunded students.
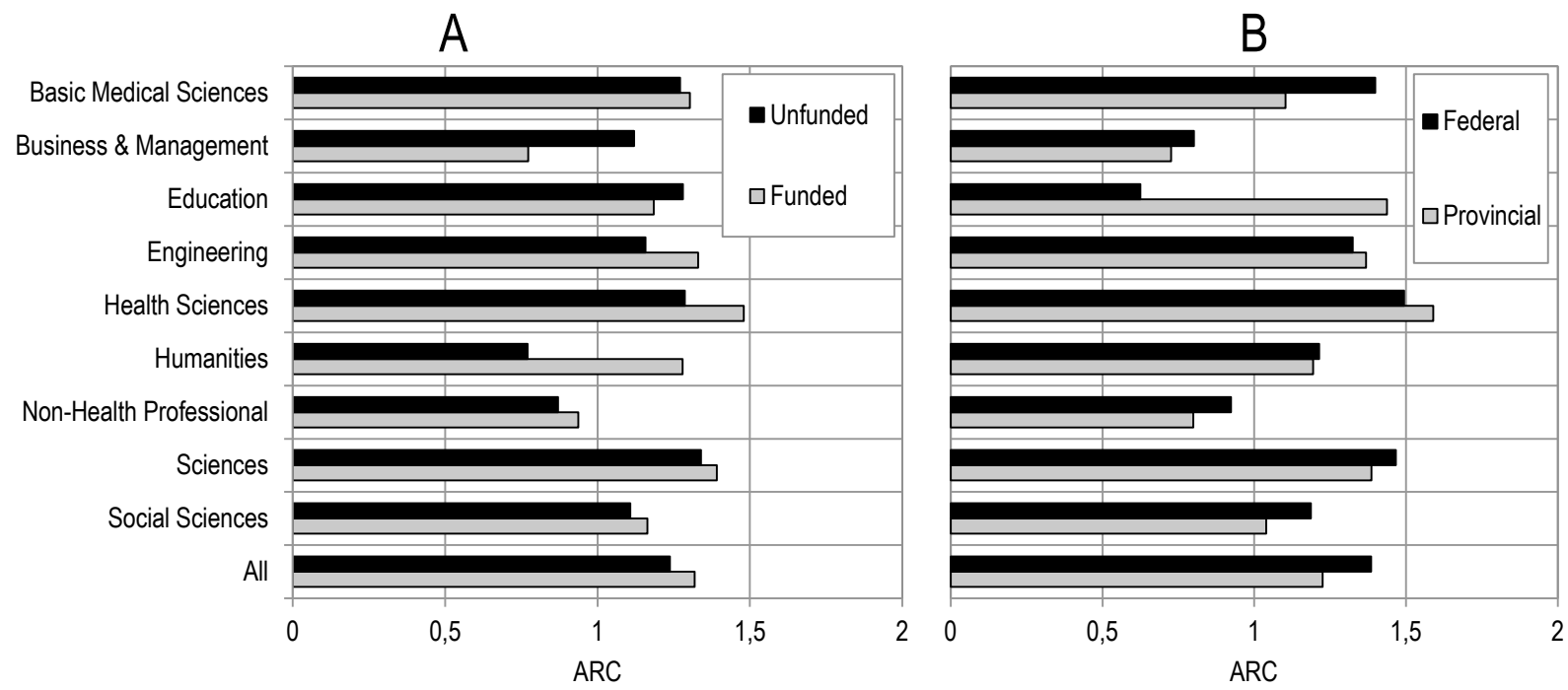

Figure 3. Comparison of average relative citations: A) Average of relative citations of papers to which funded and unfunded students contributed, and B) Average of relative citations of papers to which federally- and provincially-funded students contributed, 2000-2007.

The difference between the research impact of federally and provincially funded students is greater when taken at the level of all disciplines combined: While the papers of federally funded students obtain an ARC score of 1.39-39\% greater than the world average of their specialty-those funded by provincial councils obtain an ARC of $1.23-23 \%$ greater than the world average. This is not true, however, in disciplines such as education, engineering, and the health sciences. Despite the different patterns observed in these individual disciplines, it appears that federal councils have managed, in the 6 disciplines that account for more than $75 \%$ of doctoral students, to fund students who contributed to papers with a greater scientific impact. This can be explained by the fact that students who get both scholarships-and are thus probably the best students-have to accept the federal one, and, consequently, liberate a provincial grant, which can then be attributed to the next student on the list. 


\section{Degree Completion}

The funding of doctoral students has been previously linked to degree completion (Bowen \& Rudenstine, 1992; Ehrenberg \& Mavros, 1995; Ethington \& Pisani, 1993). Data presented in Figure 4.A points in the same direction: In all disciplines, funded students of the 2000-2002 cohorts (6,596 distinct students) were more likely to have graduated as of the end of 2007 than their unfunded colleagues of the same cohorts. More specifically, while slightly more than $50 \%$ of the funded students from these cohorts graduated as of the end of 2007, this percentage drops to $34 \%$ for those who were not funded by any of the six research councils. Although some of those who had not graduated by the end of 2007 may have since graduated, they would have taken longer than the five years usually allocated for the completion of a PhD.

Figure 4.B presents completion rates of students funded by federal and provincial councils. Although the difference in the research productivity and impact between federally and provincially funded $\mathrm{PhD}$ students was somewhat mitigated-those funded by the federal government were not always the most productive or impactful-we can see a clear trend toward degree completion for students funded by federal research councils.
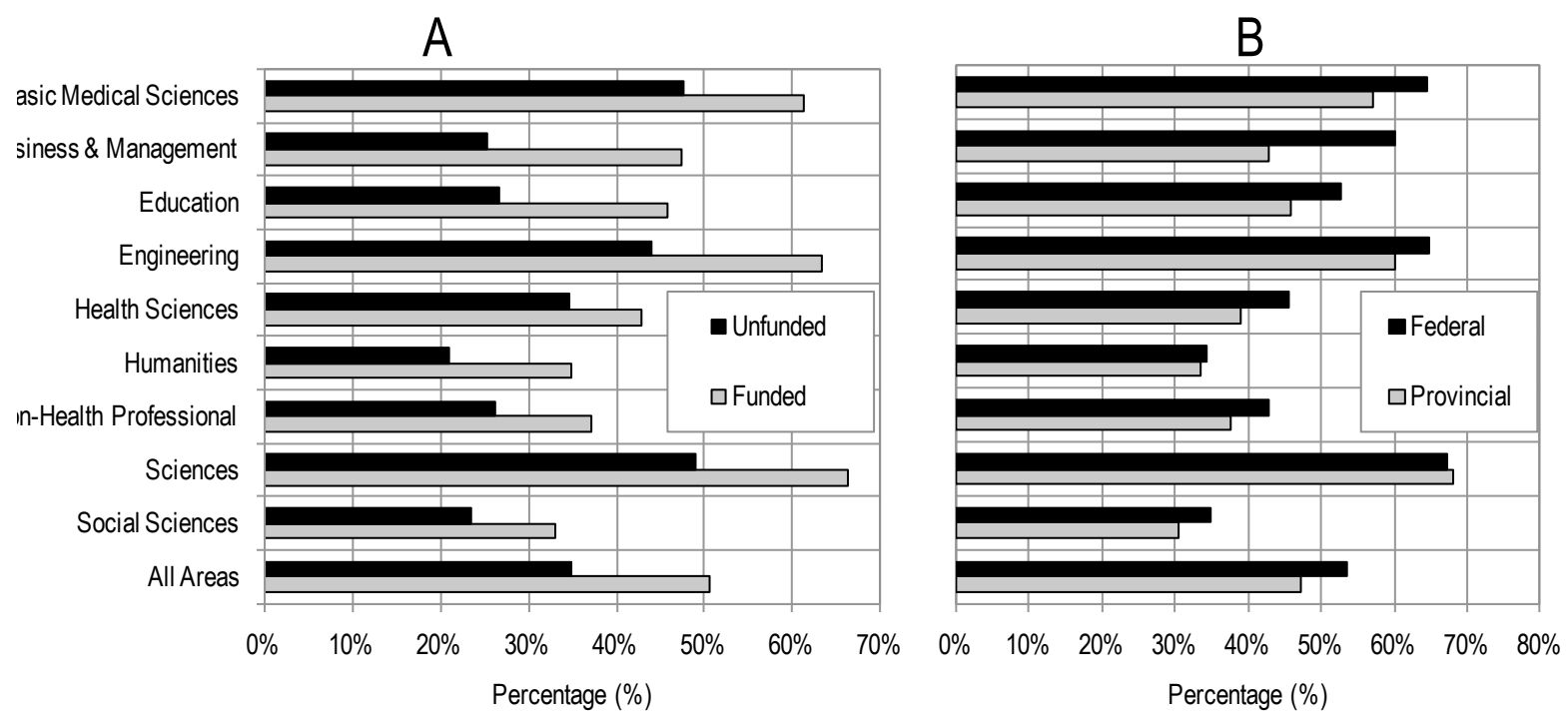

Figure 4. Degree completion (as of 2007) as a function of funding: A) Percentage of funded and unfunded students of the 2000-2002 cohorts who completed their degree, and B) Percentage of federally- and provincially-funded students of the 2000-2002 cohorts who completed their degree.

To take into account the relative importance of both publishing papers and receiving a scholarship on completion rate, we present - both for funded and unfunded $\mathrm{PhD}$ students-the percentage of students who graduated as a function of their number of publications (Figure 5). Although funded students who publish no papers are more likely than their unfunded colleagues to graduate, there is no difference in the completion rates of 
funded and unfunded students who do publish. Moreover, when limited to students who published between one and five papers, unfunded students attain higher completion rates than funded students! The figure also shows that there is a linear relationship between the number of papers published and completion rates, and that this relationship stabilizes between $70 \%$ and $80 \%$ for those who published more than five papers.

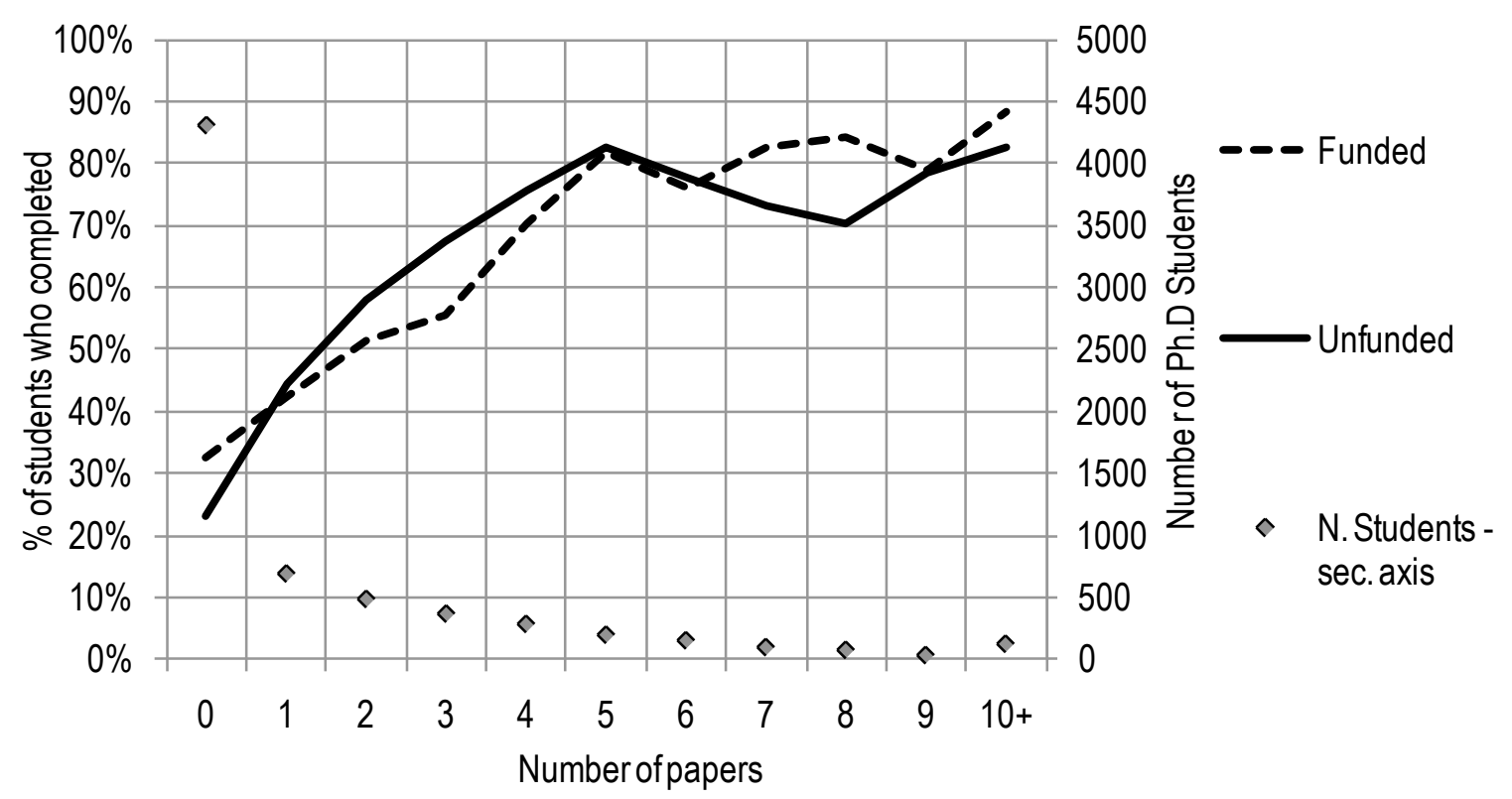

Figure 5. Percentage of funded and unfunded students of the 2000-2002 cohorts who graduated as of the end of 2007 , as a function of their number of papers.

\section{Discussion and Conclusion}

Drawing on three heterogeneous sources of data (student data, funding data and publication data) related to the entire population of doctoral students in the province of Québec, this paper examined the relationship between research funding and research productivity, scientific impact, and degree completion. Although the evidence indicates that funded students publish more papers than their unfunded colleagues, there is no meaningful difference between those funded by federal scholarships and those funded by provincial scholarships. In terms of scientific impact, there is only a slight difference between funded and unfunded PhD students, but students funded by federal scholarships obtain significantly greater impact scores than those funded by the provincial government. It cannot be assessed, however, whether this is due to their higher rank within the councils' ranking-and hence, pre-doctoral record or "excellence"-or if it is an effect of the scholarship per se. Funded students were also more likely to graduate, especially when funded by the federal government. Finally, although funding was clearly linked with higher graduation rates for students who did not publish, this is not true of students who managed to publish at least one paper during the course of their $\mathrm{PhD}$, which suggests that student integration into research-as measured by the participation in peer-reviewed papers-has a more pronounced influence on graduation rates than scholarships. 
On the whole, these data call for a reflection on the hierarchy of scholarship programs in Canada. Our data show that, despite receiving more substantial funding, federally funded students do not publish more than their provincially funded colleagues. Productivity depends on the number of researchers (Abt, 2007), and receiving funds allows doctoral students to devote time to their research. Similarly, although there is only a small difference in the graduation rates of students funded by the federal and the provincial councils, there is a clear difference in the graduation rates of funded and unfunded PhD students. Hence, instead of awarding elite doctoral students higher scholarships, funding programs should offer only one scholarship amount and use the supplementary resources to fund more students, which would likely have the effect of increasing graduation rates and, in turn, the research capacity of the country. In light of these findings, the Canadian government's recent creation of the Vanier Scholarship, which provides an elite group of $\mathrm{PhD}$ students a tax-free scholarship of $\$ 150,000$ over three years, is ill advised.

\section{References}

Abt, H. (2007). The publication rate of scientific papers depends only on the number of scientists. Scientometrics, 73, 281-288.

Ali, M.M., Bhattacharyya, P., \& Olejniczak, A.J. (2010). The effects of scholarly productivity and institutional characteristics on the distribution of federal research grants. The Journal of Higher Education, 81, 164-178.

Archambault, É., Vignola-Gagné, É., Côté, G., Larivière, V., \& Gingras, Y. (2006). Benchmarking scientific output in the social sciences and humanities: The limits of existing databases. Scientometrics, 68, 329-342.

Berk, R.A., Western, B., \& Weiss, R.E. (1995). Statistical Inference for Apparent Populations. Sociological Methodology, 25, 421-458.

Biagioli, M. (2003). Rights or rewards? Changing frameworks of scientific authorship. In M. Biagioli \& P. Galison (Eds.), Scientific authorship: Credit and intellectual property in science (pp. 253-279). New York and London: Routledge.

Bornmann, L., \& Daniel, H.D. (2005). Selection of research fellowship recipients by committee peer review. Reliability, fairness and predictive validity of Board of Trustees decisions. Scientometrics, 63, 297-320.

Bowen, W.G., \& Rudenstine, N.L. (1992). In Pursuit of the PhD. Princeton: Princeton University Press.

Boyack, K.W., \& Borner, K. (2003). Indicator-assisted evaluation and funding of research: Visualizing the influence of grants on the number and citation counts of research papers. Journal of the American Society for Information Science and Technology, 54, 447-461.

Buchmueller, T.C., Dominitz, J., \& Hansen, W.L. (1999). Graduate training and the early career productivity of PhD economists. Economics of Education Review, 14, 65-77.

Campbell, D., Picard-Aitken, M., Côté, G., Caruso, J., Valentim, R., Edmonds, S., Williams, G.T., Macaluso, B., Robitaille, J.P., Bastien, N., Laframboise, M.C., Lebeau, L.M., Mirabel, P., Larivière, V., \& Archambault. É. (2010). Bibliometrics as a performance measurement tool for research evaluation: The case of research funded by the National Cancer Institute of Canada. American Journal of Evaluation, 31, 66-83. 
CNCS-FEUQ (2008). Le doctorat en question: portrait statistique, formation, encadrement, qualité. Montréal : Conseil national des cycles supérieurs, Fédération étudiante universitaire du Québec.

Cowger, C.D. (1984) Statistical Significance Tests: Scientific Ritualism or Scientific Method? Social Service Review, 58, 358-372.

CSE (2010). Pour une vision actualisée des formations universitaires aux cycles supérieurs. Québec : Conseil supérieur de l'éducation.

Ehrenberg, R.G., \& Mavros, P.G. (1995). Do doctoral students' financial support patterns affect their times-to-degree and completion probabilities. The Journal of Human Resources, 30, 581-609.

Ethington, C.A., \& Pisani, A. (1993). The RA and TA experience: Impediments and benefits to graduate study. Research in Higher Education, 34, 343-354.

Kline, R.B. (2004). Beyond Significance Testing: Reforming Data Analysis Methods in Behavioral Research. Washington, DC: American Psychological Association.

Larivière, V. (2010). A bibliometric analysis of Québec's PhD students' contribution to the advancement of knowledge. PhD thesis, McGill University. Retrieved December 252010 at http://www.ost.uqam.ca/Portals/o/docs/Monographies/Thesis_Lariviere_ Final.pdf

Larivière, V. (2012). On the shoulders of students? The contribution of PhD students to the advancement of knowledge, Scientometrics, 90, 463-481.

Larivière, V., Archambault, É., Gingras, Y., \& Vignola-Gagné, É. (2006). The place of serials in referencing practices: Comparing natural sciences and engineering with social sciences and humanities, Journal of the American Society for Information Science and Technology, 57, 997-1004.

Larivière, V., Macaluso, B., Archambault, É., \& Gingras, Y. (2010). Which scientific elites? On the concentration of research funds, publications and citations, Research Evaluation, 19, 45-53.

Moed, H.F. (1996). Differences in the construction of SCI based bibliometric indicators among various producers: a first overview. Scientometrics, 35, 177-191.

Moed, H. F. (2005). Citation analysis in research evaluation. Dordrecht: Springer.

Moed, H.F., De Bruin, R.E., \& van Leeuwen, Th.N. (1995). New bibliometric tools for the assessment of national research performance: database description, overview of indicators and first applications. Scientometrics, 33, 381-422.

Nettles, M.T., \& Millett, C.M. (2006). Three magic letters: Getting to PhD Baltimore: Johns Hopkins University Press.

Peritz, B. (1990). The citation impact of funded and unfunded research in economics. Scientometrics, 19, 199-206.

Schubert, A., \& and Braun, T. (1986). Relative indicators and relational charts for comparative assessment of publication output and citation impact. Scientometrics, 9, 281-291. 


\section{Notes}

1. These data were compiled with http://www.outil.ost.uqam.ca/CRSH (social sciences and humanities) and, http://www.outil.ost.uqam.ca/CRSNG for the natural sciences and engineering, while the data for the medical sciences comes from an in-house database transferred by the Canadian Institutes of Health Research.

2. These limitations were also discussed by Bornmann and Daniel (2005).

3. This paper does not draw on a sample of PhD students but, rather, on the entire population of PhD students in the province of Québec for the 2000-2007 period. Hence, inferential statistical tests typically used in sample-based research are not provided, as there is no random or sampling error to assess or an "outside" population that could behave differently. For more details on the use of inferential statistics and population data see Cowger (1984), Klein (2004), and Berk, Western \& Weiss (1995), among others.

4. The only exceptions are Canada Graduate Scholarships (federal level), which can be only obtained by students enrolled in a Canadian university.

5. The numbers in columns do not add up as some students are affiliated to more than one doctoral program, which in some cases are in more than one discipline.

\section{Acknowledgement}

The author wishes to thank Yves Gingras, Benoit Macaluso, Jean-Pierre Robitaille, Laurent Viau, as well as the two anonymous reviewers, for comments and suggestions on an earlier draft of this paper. Support from the Conseil national des cycles supérieurs of the Fédération étudiante universitaire du Québec (FEUQ) is acknowledged.

\section{Contact Information}

Vincent Larivière

EBSI, Université de Montréal

Canada

vincent.lariviere@umontreal.ca

Vincent Larivière is assistant professor at the École de bibliothéconomie et des sciences de l'information (EBSI) of the Universite de Montréal, where he holds the Canada Research Chair on the transformations of scholarly communication. He is also an associate researcher at the Observatoire des sciences et des technologies (OST) and a regular member of the Centre interuniversitaire de recherche sur la science et la technologie (CIRST). His research focuses on the transformation of the modes of production and diffusion of scholarly research. 